\title{
Developing benchmark standards for inspecting and reporting on the condition of walls in traditional residential properties
}

Received (in revised form): 22nd April, 2005

\section{Larry Russen}

is a chartered building surveyor who works in private practice, carrying out surveys, structural reports, defects diagnosis and associated work. He is a director of Russen \& Turner in King's Lynn and board member of Allied Surveyors plc. For a number of years he has been actively involved in a minor way in setting standards for surveyors as a member of the Surveyors and Valuers Association (SAVA) Benchmarking and Training Panel. He is currently an assessor with the SAVA assessment centre for Home Inspectors and is a part-time lecturer at the College of West Anglia in King's Lynn.

\begin{abstract}
The objectives of this paper are to impart some basic information on the subject of walls in traditional residential properties and to suggest that the Building Regulations and other readily available and published documentation can and should be used by surveyors as 'benchmarks' of good practice when inspecting and reporting on not only new but also older types of property. Indeed, modern standards can be used to put older buildings into context such that in many instances those buildings can be satisfactorily compared with new properties.
\end{abstract}

\section{Keywords:}

walls, professional attitude, attention to detail, consistency, Building Regulations

\section{INTRODUCTION}

This paper developed out of a series of all-day lectures given on behalf of SAVA, one of the specific 'learning outcomes' for the students being that at the end of the session they should be able to 'conduct the inspection in a thorough, methodical and consistent manner'. To this end, it is suggested that for any surveyor, if they are to achieve this goal, it

Larry Russen

Russen \& Turner 17 High Street King's Lynn PE30 1BP, UK Tel: +44 (o) 1553768187 Fax: +44 (o) 1553767971 E-mail: larry. russen@russenandturner.co.uk is a fundamental requirement to:

- know exactly what they are looking at, ie what form of construction;

- inspect very carefully, ie be 'thorough, methodical and consistent';

- record findings, construction and defects in a logical way;

- draw conclusions based on careful analysis of all the data (and not jump to conclusions). 
After reflection, they also should be able to:

- maintain and develop a professional attitude and employ attention to detail in all inspections.

It is further suggested that too many surveyors, over the years, have relied on 'gut feeling' and a lack of precision, whereas in fact there is a considerable quantity of published documentation which has always been available, if only surveyors know where to find it.

The primary purpose of this paper is to demonstrate that good

The importance of available sources of information information is available to help any surveyor in their diagnosis of defects, condition and compliance with modern standards and requirements. It can be demonstrated that the best sources of information in this regard are modern benchmark standards, such as the Building Regulations, British Standard (BS) Codes of Practice or National House-Building Council (NHBC) standards. One argument against such a proposition is 'how on earth can you use a modern standard to survey and assess an old building of, say, 200 years in age?'. But it is contended that any modern benchmark is simply a standard against which any property of any age can be measured. Indeed, in today's climate (if readers will forgive a poor, but perhaps apposite, reference to global warming), it is possibly even more important for the modern surveyor to be aware of the standards expected or anticipated by the general public.

Is it not perhaps the case that one of the main driving forces behind the Home Information Pack might be to encourage everyone to help improve the housing stock? Witness current government proposals to rebuild large areas of some cities, because the older housing stock is not 'up to standard'. But what are those standards? How much better for the surveyor if there is good, solid, technically based information upon which to rely, rather than a 'feeling' which may, admittedly, have developed over many years' experience. But then how much better if such experience is underpinned by technical knowledge?

The use and knowledge of modern benchmarks need not mean necessarily that an old property is immediately condemned out of hand. Far from it, because knowledge of such standards means the surveyor can put the property, its construction, condition and facilities into context when compared with, for example, those modern standards which are increasingly important, eg Standard Assessment Procedure (SAP) ratings.

\section{BENCHMARKS FOR SURVEYS}

For any survey, be it an Homebuyers Survey and Valuation (HSV), Home Condition Report (HCR) or building survey, a good document to start with is the Royal Institution of Chartered Surveyors (RICS, 2004) Guidance Note for Building Surveys. This is because all surveys require, in effect, the same level of knowledge, attention and expertise, ie the standard of care for an HSV is the same as for a building survey. Why is this important? Given that many in the industry are currently of the view that the HCR will be a 'level 2' inspection, perhaps everyone needs to be 
reminded of what Judge Phillips said in Cross $v$ Mortimer: 'We are convinced that the same level of expertise is required from the surveyor in carrying out an Home Buyers Report and Valuation (HBRV) as that for a structural survey'.

Post January 2007, how long will it be before another eminent and learned judge makes the same link between the HCR and the structural/building survey/HSV, particularly when a barrister who is aware of the 'current word on the street' reminds him?

In this regard, the RICS Guidance Note includes a recommendation to inspect, consider and discuss construction principles such as main loadbearing structures, elements giving lateral restraint, load paths, flexible and rigid structures, structural framework and the likely condition of foundations. There is also a requirement to consider the structural framework in an 'overall assessment'. It is considered necessary to consider conformity with modern requirements. The Guidance Note further requires that a surveyor must take into account the likely scale of future maintenance (RICS, 2004).

Given, then, a need to consider matters such as 'conformity with modern requirements', surely a surveyor must know something about those requirements, whatever they are?

\section{Walls - The absolute basics}

It is suggested that the three main purposes of a wall are:

- Stability: to support floor and roof loads and transfer them to the foundations via the 'load paths'; this may be undertaken by either external or internal walls.

- Environmental protection: by prevention of water ingress and other weather; this requirement applies to both cavity and solid outer walls.

- Thermal resistance is particularly important nowadays.

\section{The best benchmark of all - The Building Regulations}

'Conformity with modern requirements' and knowledge thereof, is best achieved by regularly having access to this document. Indeed, the Building Regulations almost seem to have been set out for the benefit of surveyors.

Regulation A2 of Approved Document (AD) 'A' requires that buildings should be constructed in such a way that ground movement such as subsidence or landslip 'will not impair the stability of any part of the building'. Regulation A1 further requires that the building should be constructed so that the combined dead, imposed and wind loads are sustained and transmitted by it to the ground without causing or allowing any 'deflection or deformation of any part of the building'.

Well, the Office of the Deputy Prime Minister (ODPM) has the requirements in slightly the wrong order if one considers foundations first and walls above ground second; but here is an absolute benchmark against which to measure any residential building.

'But this is all very well', readers may mutter, but 'what help is this and how can I actually apply these hopelessly general rules on site whilst being 
bitten by a Doberman and drinking the proffered weak tea?'. Well, the beauty of the ADs in the Building Regulations is that having postulated the ideal, against which to measure the property being inspected, the documents then go on to describe, in relatively simple terms, how the property can be made to so conform. Following are some examples.

\section{Structural framework}

The Regulations deal in some considerable detail with ensuring that the building is stable 'under the likely imposed and wind loading conditions' and then go on to specify certain basic requirements. Paragraph 2A2 includes a general requirement for sizes of walls and structural members in 'low rise residential buildings', including in turn a 'suitable layout of walls (both internal and external) forming a robust three dimensional box structure in plan'.

A further requirement is that 'internal and external walls are adequately connected by either masonry bonding or by using mechanical means ... the intermediate floors are of such construction and interconnection with the walls that they provide local support to the walls and also act as horizontal diaphragms capable of transferring the wind forces to buttressing elements of the building'.

It is suggested that this most basic of requirements for any building

\section{Guidance provided by Building Regulations} is equivalent in many ways to the 'structural framework' requirement in the RICS guidance, which, as has been indicated above, any surveyor carrying out a survey must assess. The Regulations continue elsewhere to give specific guidance in this regard - put very simply there is a general need to tie the building in by ensuring that there is lateral restraint provided to outer walls by a combination of buttressing walls, chimney breasts, floors and straps. All of such requirements are capable of being surveyed and measured on site by a competent surveyor.

But this is not all; the Regulations are literally littered with little gems (or 'nuggets' as that other excellent proponent of the use of the Building Regulations and superb speaker, Simon Pitchers, structural engineer, calls them). For example, paragraph $2 \mathrm{~A} 2$ of $\mathrm{AD}$ ' $\mathrm{A}$ ' includes the advice that:

\footnotetext{
'A traditional cut timber roof (ie using rafters, purlins and ceiling joists) generally has sufficient built in resistance to instability to wind forces (eg from hipped ends, tiling battens, rigid sarking, or the like). However, the need for diagonal rafter bracing equivalent to that recommended in BS 5268: Part 3: 1998 or Annex H of BS 8103: Part 3: 1996 for trussed rafter roofs, should be considered especially for single-hipped and non-hipped roofs of greater than $40^{\circ}$ pitch to detached houses.'
}

This rule is clearly of use when considering the requirements for lateral restraint, as well as in relation to roofs of course. Thus, it is suggested that this is another excellent 'benchmark' to use for all of those old houses where those particular circumstances apply; but the point is that the surveyor will not know about this rule if he takes the view that 'I am a Building Surveyor/Home Inspector, I don't need to know about the Building Regulations as I am not involved in design'. 


\section{Solid walls}

\section{Cavity walls}

\section{Thickness of walls}

Students of 'slenderness ratio' and BS 5628: Code of Practice for Structural Masonry: Part 3: 2001 will recognise that it has long been accepted theory and practice that the taller a wall is in relation to its thickness, the more propensity it has to fall over.

Paragraph 2C6 of AD 'A' states that 'solid walls constructed of coursed brickwork or blockwork should be at least as thick as 1/16th of the storey height'. Now here is another 'nugget' of information. Furthermore, it is contended that not only is this a veritable nugget, but it suggests a goldmine, for what on earth is a modern document doing describing buildings with walls of solid construction? Some may say 'You can't design and build a new building with solid walls, since they let the water through!'. Wrong, but no matter, forget the whys and wherefores, the information is there, so one should use it.

When a standard brick wall of $225 \mathrm{~mm}$ thickness is multiplied by 16 the answer is $3,600 \mathrm{~mm}$. This is considerably more than the storey height of most old houses that are inspected day in, day out by chartered surveyors and would-be Home Inspectors. Now, the Regulations go on to require that such walls, if they are to be considered stable, must be provided with lateral restraint at upper floor level (of which more later), and there are many more requirements. The point is that by using a modern benchmark, it is possible to assess an old building.

Surveyors no longer need to 'hang their hat' on old maxims such as 'I've looked at lots of houses like this in the past and they all stood tall and proud, this one will be ok'. Instead, they are able to assess a property based on some sound engineering advice. For the Regulations are based on the previous knowledge and experience of generations of past surveyors, architects, engineers, contractors etc, contained in the BSs upon which so many of the Regulations are based.

Paragraph 2C7 goes on to state that, for solid walls, 'the thickness of walls in uncoursed stone, flints, clunches, of bricks or other unburnt or vitrified material should not be less than 1.33 times the thickness determined by paragraph 2C6'. Again, a simple calculation based on this paragraph in relation to many older buildings will reveal that they comply with 'modern requirements'. Thus, far from condemning older buildings by using modern standards and benchmarks, in practice considerable comfort is provided to the surveyor from knowledge of those modern standards when inspecting older dwellings.

What of modern cavity walls? The Regulations treat them pretty much the same as solid walls: 'the combined thickness of the two leaves plus $10 \mathrm{~mm}$ should not be less than the thickness determined by (the rules applying to solid walls)' (paragraph 2C8). For those properties with cavity walls then, the Regulations make it easy for surveyors because they only need to remember the $1 / 16$ th rule.

\section{Length and height of walls}

Table 3 of AD ' $A$ ' is set out as Figure 1. Once translated into something which can be used as a 'ready reckoner' for surveyors on site (Figure 2), 


\begin{tabular}{|c|c|c|c|}
\hline \multirow{2}{*}{$\begin{array}{l}\text { Table } 3 \\
\text { Height of wall }\end{array}$} & \multicolumn{3}{|c|}{$\begin{array}{l}\text { Minimum thickness of certain external walls, compartment walls and } \\
\text { separating walls }\end{array}$} \\
\hline & & Length of wall & Minimum thickness of wall \\
\hline not exceeding 3 & & not exceeding $12 \mathrm{~m}$ & $190 \mathrm{~mm}$ for whole of th height \\
\hline \multirow{2}{*}{\multicolumn{2}{|c|}{ exceeding $3.5 \mathrm{~m}$ but not exceeding $9 \mathrm{~m}$}} & not exceeding om & $190 \mathrm{~mm}$ for whole of th height \\
\hline & & exceeding $9 m$ & $\begin{array}{l}290 \mathrm{~mm} \text { from the based for the height of } \\
\text { one storey and } 190 \mathrm{~mm} \text { for the rest of th height }\end{array}$ \\
\hline \multirow{2}{*}{\multicolumn{2}{|c|}{ exceeding 9m but not excesding 12m }} & not exceeding ?m & $\begin{array}{l}200 \mathrm{~mm} \text { trom the based for the height of } \\
\text { one storey and } 190 \mathrm{~nm} \text { m tor the rest of fits height: }\end{array}$ \\
\hline & & $\begin{array}{l}\text { excesding } 9 \mathrm{~m} \\
\text { butrot exceding } 12 \mathrm{~m}\end{array}$ & 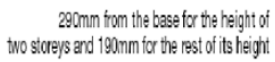 \\
\hline
\end{tabular}

Figure 1: Table 3 from the Building Regulations Approved Document ' $A$ '

this represents a document that can be used to assess all walls, based on BS 5628: Part 3: 2001.

It can be noted that the wall thicknesses fall comfortingly well within the standard thicknesses of the usual $225 \mathrm{~mm}$ and $325 \mathrm{~mm}$ ( 9 feet and 13.5 feet) solid brick walls that make up so much of the UK housing stock and, again if properly applied, should give comfort and guidance to anyone carrying out inspections. Just think of all those Victorian houses with brick and a half walls at ground floor and/or first floor level, reducing to single brick (9 feet) at upper floor level. Here is a firm benchmark to measure them against, courtesy of years of accumulated experience.

But a word of warning, the assumptions that are made in the Regulations include provision of lateral restraint, at floor and roof level

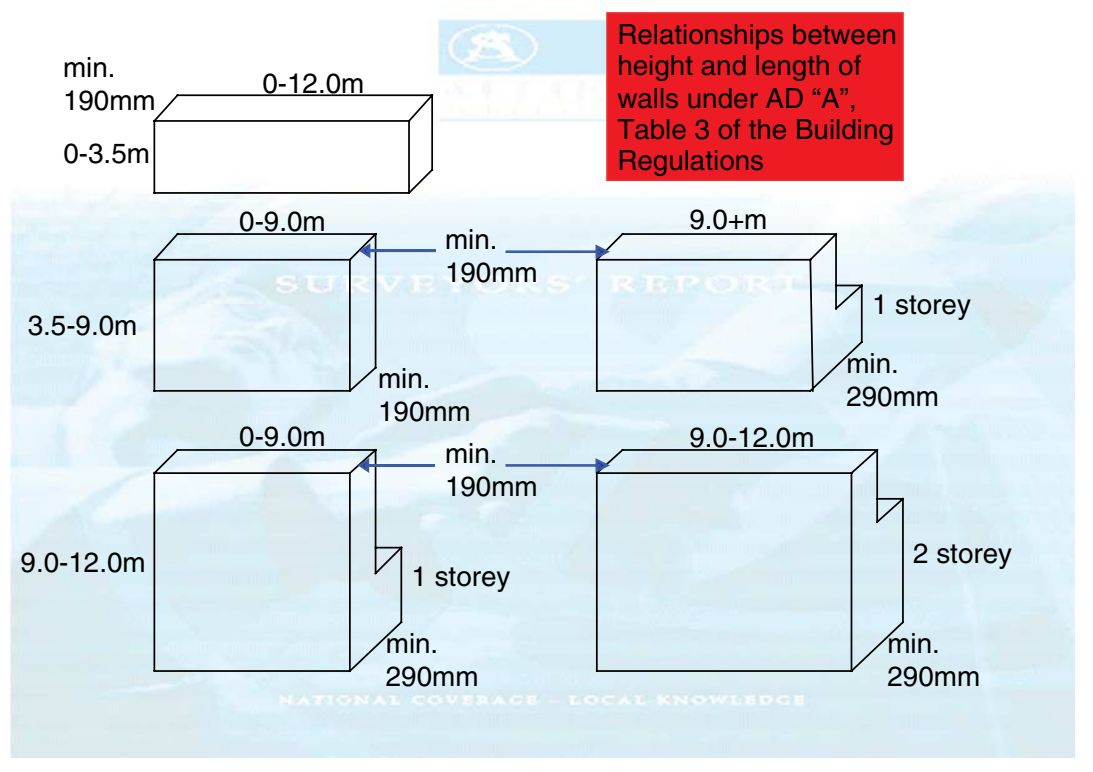

Figure 2: Table 3 'translated' into simple diagrammatic form 
(as required by the relevant Code of Practice, BS 5628), and the rules must be applied also with full knowledge of other requirements relating to matters such as window and door openings, all of which information is in the Regulations and which is not included in this paper for want of space.

\section{Wall ties}

Since December 2004 the general rule is that all new housing (depending on the date of the approval) must use 'austenitic stainless steel'. Inspection within cavities may not currently be the norm, but this is surely fundamental knowledge and should be filed way for use at a later date, eg for use in relation to consideration of matters such as cavity wall tie corrosion.

Clearly, readers will be aware of the fact that ties installed prior to around 1981 (the year in which the standard of galvanising was improved) have a significant risk of corrosion and the writer has found instances of such problems in properties built as early as 1976, albeit in a marine environment.

\section{Wind speeds}

Diagram 6 from the Building Regulations AD 'A' is reproduced as Figure 3 and, when combined with Diagram 7 (Figure 4), can be used to calculate maximum heights of buildings allowing for topography etc. As with all of the other information in the Regulations, care must be taken and common sense applied. Based on the guidance provided, the writer's bungalow should have collapsed many years ago! But it is suggested that wind speeds are likely to become more of a factor for consideration in the future, with global warming and apparent increases in average wind speeds.

Some good background knowledge on the subject still can be put to good use and the simple steps to arriving at an adjusted wind speed which are given in Diagram 7 (allowing for the ODPM's spelling errors) will enhance the surveyor's knowledge and awareness of potential problems in the locality.

For example, perhaps cracking on the gable end in an old farmhouse being inspected on the moor, next to a steep hill, incapable of being diagnosed in any other way, can be attributed to the wind loading on the gable? Or, is it possible that the water penetration on the same gable, excessive in the surveyor's experience for that style of house, can be explained by the wind-driven rain, the speed of which the surveyor is now more aware of as a result of increased knowledge of that best practice benchmark, the Building Regulations? Not forgetting the help such information will be when considering the roof and all of those unnailed tiles. Again, the point is that armed with this information consideration of a building should not only include a tick box either on the site/report notes relating to 'wind', but the details in $\mathrm{AD}$ ' $\mathrm{A}$ ' give firm information upon which to base an opinion, based on fact. 


\section{Diagram 6 Map showing wind speeds in $\mathrm{m} / \mathrm{s}$ for maximum height of buildings}

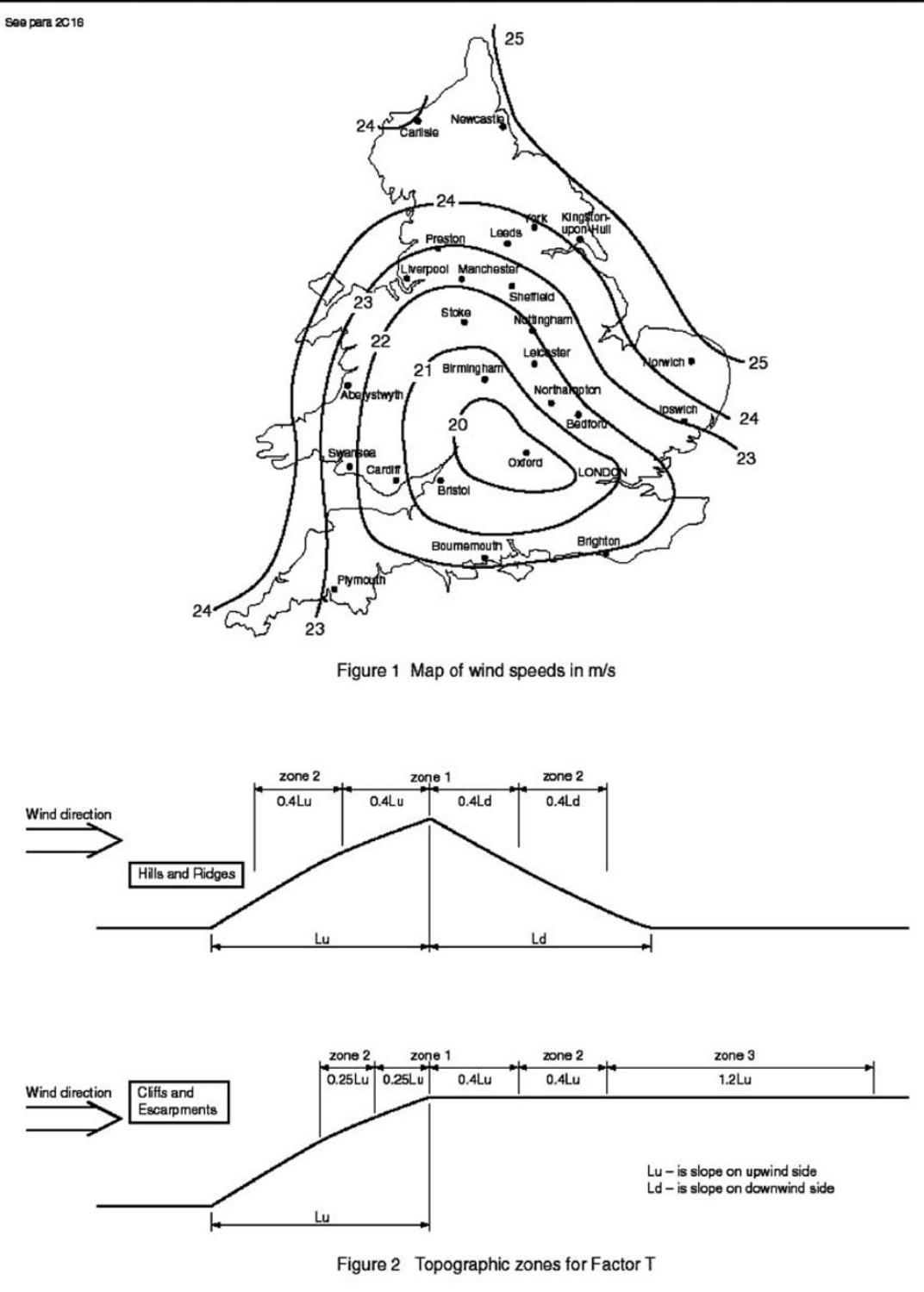

Figure 3: Diagram 6 from the Building Regulations Approved Document 'A'

\section{Lateral restraint}

The rules regarding lateral restraint are necessarily complicated, but must be related back to the requirement for a 'rigid box-like structure'. They can be summed up as requiring all walls to be tied in at floor and roof level either by timbers built into the walls (where the joists etc bear in the walls) or by straps at $2 \mathrm{~m}$ centres.

In older buildings, it is suggested that structural details such as tie bars, perhaps indicated by the presence of pattress plates to straps or straps attached to purlins within roof spaces, and tie beams can be treated reasonably and with care in a similar fashion. Where such details are 


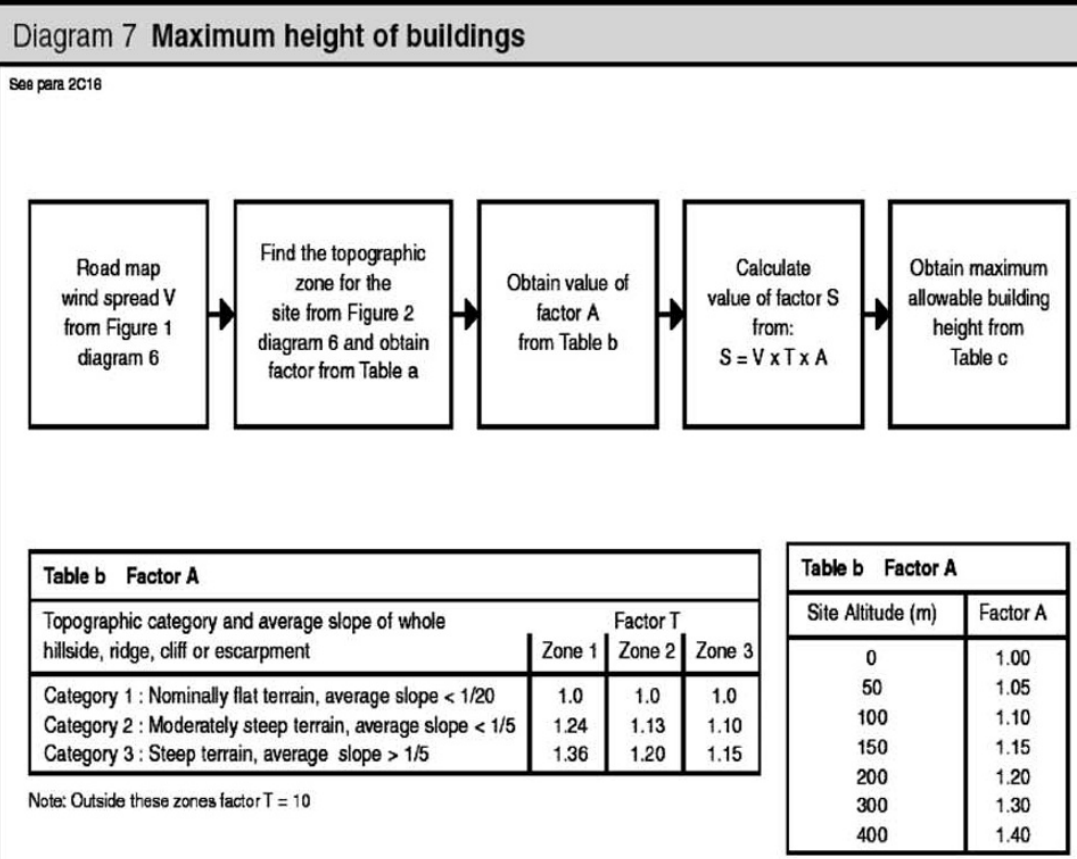

\begin{tabular}{|c|c|c|c|c|c|c|}
\hline \multicolumn{2}{|c|}{ Table c Maximum allowable building height (m) } \\
\hline Factor & \multicolumn{3}{|c|}{ Country Sites } & \multicolumn{3}{c|}{ Town Sites ${ }^{*}$} \\
\hline S & \multicolumn{3}{|c|}{ Distance to the coast } & \multicolumn{3}{c|}{ Distance to the coast } \\
& $<10 \mathrm{~km}$ & $10-50 \mathrm{~km}$ & $>50 \mathrm{~km}$ & $<10 \mathrm{~km}$ & $10-50 \mathrm{~km}$ & $>50 \mathrm{~km}$ \\
\hline 24 & 15 & 15 & 15 & 15 & 15 & 15 \\
25 & 11.5 & 14.5 & 15 & 15 & 15 & 15 \\
26 & 8 & 10.5 & 13 & 15 & 15 & 15 \\
27 & 6 & 8.5 & 10 & 15 & 15 & 15 \\
28 & 4.5 & 6.5 & 8 & 13.5 & 15 & 15 \\
29 & 3.5 & 5 & 6 & 11 & 13 & 14.5 \\
30 & 3 & 4 & 5 & 9 & 11 & 12.5 \\
31 & & 3.5 & 4 & 8 & 9.5 & 10.5 \\
32 & & 3 & 3.5 & 7 & 8.5 & 9.5 \\
33 & & & 3 & 6 & 7.5 & 8.5 \\
34 & & & & 5 & 7 & 8 \\
35 & & & & 4 & 6 & 7 \\
36 & & & & 3 & 5.5 & 6 \\
37 & & & & & 4.5 & 5.5 \\
38 & & & & & 4 & 5 \\
39 & & & & & 3 & 4 \\
40 & & & & & & 3 \\
\hline
\end{tabular}

- For sites on the outskirts of towns not sheltered by other buildings use the values for Country sites

Figure 4: Diagram 7 from the Building Regulations Approved Document 'A'

not present, or inadequate when compared with the Regulations, then this is not carte blanche to condemn the structure, but at least it is possible to consider and report with the benefit of some knowledge of basic engineering principles.

Figure 5 gives some guidance on what is required in the case of that ubiquitous gable wall which so many surveyors encounter and where they need guidance on whether or not lateral restraint at truss chord/ceiling 


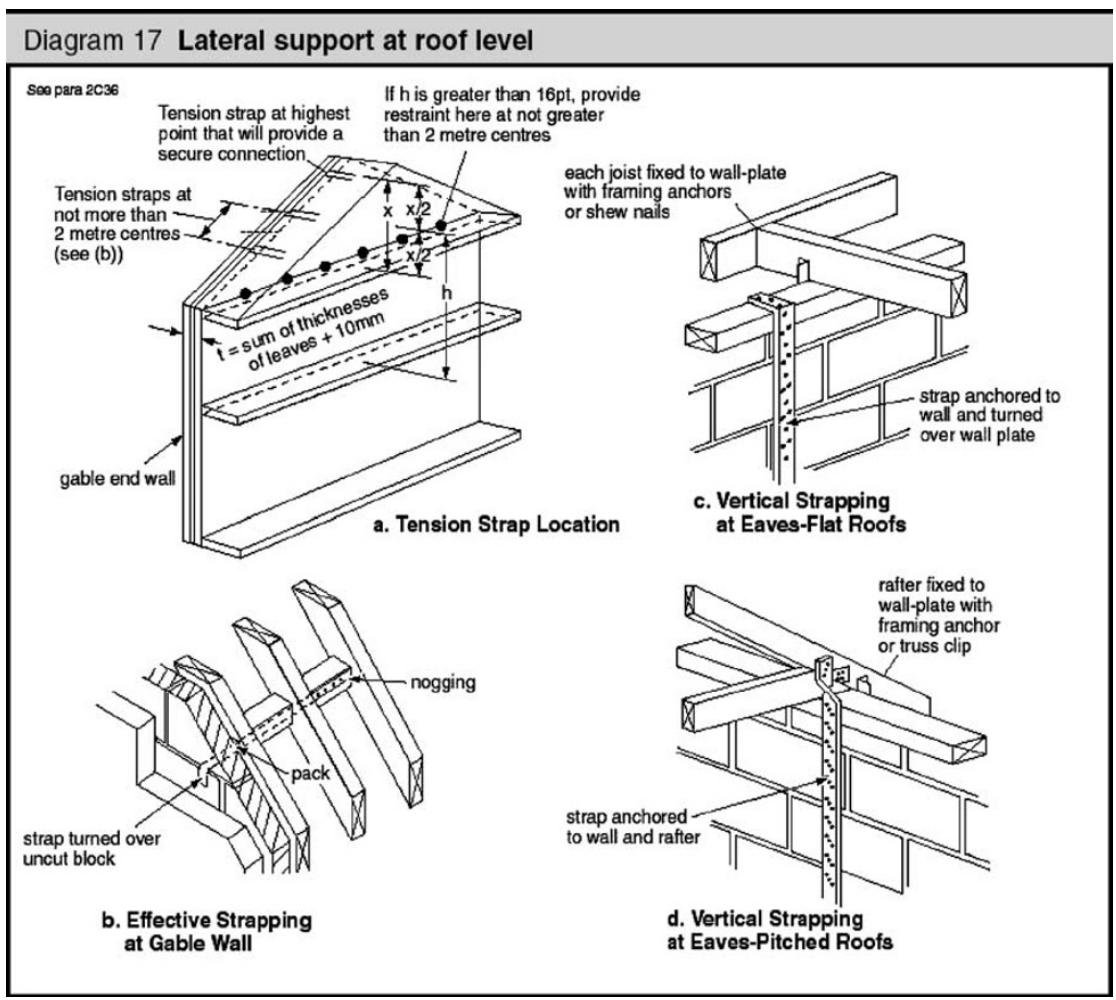

Figure 5: Diagram 17 from the Building Regulations Approved Document ' $A$ '

joist level is required (remember that the rules apply to solid walls as well as cavity walls).

The rule is fairly simple and is again based on the principle of the 'slenderness ratio' from first floor level (which is assumed to be similarly restrained) to a point midway between joist and ridge board level. If the sum of the two leaves plus $10 \mathrm{~mm}$ (or the thickness of the solid wall) is greater than 1/16th of the distance between the two points, then restraint is not required; otherwise, the ideal is that restraint is desirable.

Even if the surveyor cannot be bothered to do a rough calculation, a simple rule of thumb for most dwellings, assuming a 'BS surveyor' of average height, is that if one's head bangs on the ridge board when standing on the ceiling joists, restraint at ceiling joist level is not needed.

Another helpful item of information relating to older properties which is contained in the Building Regulations relates to that same gable wall where the surveyor is concerned about lack of lateral restraint to the wall due to the presence of a stairwell that may run for the full height against the gable. Paragraph 2C37 is concerned with 'interruption of lateral support'. Briefly, the rule is that so long as the opening for the stair is no more than $3 \mathrm{~m}$ horizontally (which is the case in many instances), then mild steel straps or equivalent support should be provided on either side of the opening in the floor or roof to the abutment between the wall and the floor/roof at centres "spaced closer than $2 \mathrm{~m}$ on each side of 
the opening to provide the same number of anchors as if there were no opening, and there should be no other interruption of lateral support'.

It is suggested that, in many cases, such support is already provided, thereby giving the surveyor some comfort. If no such support is provided and the wall is showing signs of distress attributable to lack of restraint, however, then a possible remedial action is available.

\section{A WORD ON CRACKING}

One of the most difficult tasks for surveyors is identifying the age of cracking and deciding on where the cause of the cracks may be found. In Cracking and Building Movement (Dickinson and Thornton, 2004), it is suggested that crack edges and sides should be investigated and:

- 'a recent crack will be more likely to be clean and have sharp crisp edges;

- an older crack is more likely to have dirt in the cracks and have softer or eroded edges;

- internal older cracks may have paint or old wallpaper on the edges of the crack and perhaps cobwebs in the cracks'.

This is excellent advice when beginning consideration of any crack, although many cracks refuse to conform to such advice and other matters need to be taken into account, such as:

- Whether the wall/crack faces towards the prevailing wind, in which case weathering will tend to occur at a quicker rate?

- Is the crack present due to seasonal movement, when a relatively thin crack can appear to be very old as a result of years of movement?

- Is there evidence of re-pointing and signs of any further cracking?

- Is the pattern of horizontal and/or vertical cracking consistent with the diagnosis of the problem?

Another useful rule referred to by Dickinson and Thornton (2004), and one used successfully by many surveyors and engineers over the years, is to map out the general pattern of movement on a sketch or in the 'mind's eye' and then draw another line at right angles to that line of movement. Simon Pitchers uses this rule, with his other 'Golden Rules of Crack Interpretation', to good effect in his lectures. The cause of the cracking sometimes can be found at either end (or both ends) of the latter line.

As ever, cracking one may encounter is rarely set out so simply, but it is surprising how often careful drawing of the cracks onto a sketch of each elevation and then application of this rule will point in the direction,

The importance of site plans literally, of the cause of the problem. A fundamental issue, in addition, is to draw a site plan. This must show walls, drains, trees, ground variations, boundaries and any features noted outside the site. Of course, it is a given that vendors/occupiers will be asked about such matters, but perhaps not upon the assumption that they will be entirely honest. 


\section{WATER PENETRATION AND DAMPNESS TO WALLS}

The new 'Bible' for all surveyors on damp is, or should be, Diagnosing Damp by Burkinshaw and Parrett (2003). This weighty volume goes into the detail that is missing in so many other books. The potential subject of another paper, it is suggested by the authors that the relatively simple moisture tests which are possible during a normal survey cannot really provide the level of certainty which most clients expect, but do provide some basic rules, most of which will be well known to most surveyors, but can be repeated here, with some additional information, for emphasis:

- Use moisture meters with care and bear in mind that in general they only measure electrical resistance.

- Moisture meters can be 'fooled' by soluble salts.

- Penetration of rain occurs more often via the brick-mortar abutment than through brick or mortar.

- Mortars containing lime have a higher water retention capability and therefore tend to develop a better bond.

- More cement in the mortar means the wall is less permeable, but more liable to shrinkage cracks.

The Building Research Establishment (BRE) has suggested that around 10 per cent of dampness problems are actually caused by rising dampness, other causes being condensation, water penetration etc. Is this perhaps because there are some surveyors out there who have not even read the instructions for use of the damp meter?

The Building Regulations are capable of providing yet more comfort to surveyors on the subject of water penetration in old properties.

Paragraph 5.8 of $\mathrm{AD}$ ' $\mathrm{C}$ ' confirms that 'any solid wall will meet the requirement if it will hold moisture arising from rain and snow until it can be released in a dry period without penetrating to the inside of the building, or causing damage to the building'.

Suggested technical 'solutions' comprise solid walls varying between $215 \mathrm{~mm}$ lightweight blocks up to brick or stone walls of $328 \mathrm{~mm}$, both with rendered surfaces. There are any number of similar walls on older buildings which, in effect, comply with modern standards.

\section{SOME OTHER BENCHMARKS}

This paper has concentrated on the Building Regulations because they are so fundamental to any building surveyor's knowledge and skills in that they provide so much information. But there are numerous other documents with similarly useful information, including the following.

- Codes of Practice. Since the Building Regulations are based on the Codes, the Regulations should be the first source.

- NHBC Standards. This organisation has received much bad press, but the standards contain some superb details, hints and tips which are extremely helpful and Chapter 4.2 'Building near Trees' is a 'must'.

- BRE Digests. The obvious one here is Digest 251, but look at later documents such as Digest 475 relating to 'tilt'. 


\section{A proposed format for inspecting and reporting on walls}

- British Geological Survey maps are vital for good background information on soil types.

- Where possibly relevant, use historical Ordnance Survey maps which are now readily available.

\section{INSPECTION METHODOLOGY}

Each surveyor tends to develop their own method of carrying out inspections. There is no 'right' or 'wrong' way, only a method that works for the particular surveyor and, more importantly, arrives at the correct result every time. Consistency of inspection is the ideal goal. But why is this important?

It is suggested that most surveyors who carry out inspections and prepare survey reports are human. It follows that mistakes will be made. However, on those days when the surveyor is feeling under the weather or below par for whatever reasons, with the possible resultant lack of complete attention to detail, an established, tried and tested system/method of inspection allows the surveyor to have the inevitable 'bad day' which happens to everyone. This is because with such a system it is possible to operate almost on 'autopilot' with the benefit and comfort of a wellrehearsed methodology supporting one through the bad day.

The following is a suggested possible format for inspecting and reporting on walls. It is not suggested that this is the best possible approach - it is simply one adopted after many years of personal experience. There are doubtless better systems employed by other surveyors, in which respect constructive criticism is always welcome and, indeed, ideal in the ever-continuing attempt to reduce claims and complaints. Everyone should share ideas and suggestions in that regard. The fundamental point is that a surveyor should have a system and then use it and subsequently improve it, based on regular review.

- Adopt a Quality Assurance (QA) approach to the survey (and report) with a pre-prepared checklist and inspection notes.

- Regularly audit the system and incorporate improvements based on feedback/experiences/CPD/life long learning (LLL) etc.

- Break down large areas of wall into easily considered and manageable portions. Inspect each wall/partition in 'chunks' of $1 \mathrm{~m}$ or $1 \mathrm{~m}^{2}$ at a time, but remember always to consider the big picture.

- Start at the same point externally every time, eg front left-hand corner.

- Inspect around the building in the same direction during every survey, ie clockwise or anti-clockwise.

- Adopt the same rule internally, ie start at the front left-hand corner on each floor.

- Approach each building, elevation, wall, room and area (landings etc) using the same method.

- Use a spirit level at corners and elsewhere to check verticality and look upwards from corners and elsewhere on every wall; windows and parapet gutters are excellent in this regard. 
- If required, use a plumb bob, bearing in mind that this should weigh ideally at least $0.5 \mathrm{~kg}$ and be suspended in a bucket of oil (be careful of car seats).

- Consider buying one of the new laser levels, they are cheap, easily set up on site and give excellent results where confirmation of level is needed.

- Look along bed joints for horizontal perspective (lay on the ground to look along the damp-proof course if necessary).

- Use the level horizontally to inspect areas, eg sills or bed joints.

- Climb a ladder on older (or modern) properties, or to view suspect areas, taking the level with one and using it.

- Stand back and view each elevation as a whole and do the same for the whole building.

- Prepare a sketch plan and mark on load and non-load-bearing walls etc.

- Complicated building or feeling confused? Use more sketches, sections and red felt-tip pen to show cracks and directions of movement.

- Tap walls with a fist, screwdriver handle or whatever (but use the same tool for consistency) to show signs of debonding, loose materials, spalling etc, using a ladder as before (remember to pick up the loose bits).

- Scrape lightly in at least one spot on each wall's bedding/jointing mortar to establish type/condition.

- Use the level internally also, look at each wall/partition individually and then the whole room/area in totality, tap as before (this should be so ingrained it is done in other people's homes when invited to dinner!).

- Inspect, make notes on, consider and then report on areas in the following order of magnitude: below-ground movement (subsidence etc), above-ground movement (eg bulging, localised movement (eg lintels)), masonry and pointing condition.

- For damp meter readings follow the SAVA BS benchmark standards, at $1 \mathrm{~m}$ intervals to walls and floors (remember that moisture can move laterally from a damp wall into a floor, by at least $1 \mathrm{~m}$ ), in vulnerable positions such as to window and door reveals (at least two tests in each reveal and definitely to the reveals that face the prevailing wind) and to internal walls/chimney stacks which continue upwards to emerge externally and are exposed to rain.

- Always try to follow the same methodology to achieve consistency and reduce the risk of mistakes.

- Review and continually develop this system, to suit the individual, within Quality Management System (QMS)/QA constraints.

\section{CONCLUSIONS}

This paper is a scratch on the surface of the subject of walls and is intended to provoke more surveyors to develop their skills and knowledge on this vital issue. It is most definitely not a full treatment of the subject matter and the all-day, interactive lectures for SAVA are only capable of scratching the surface of the subject slightly deeper, as the breadth of knowledge and experience required is so vast. 
Those people who can still remember their basic valuation lectures will recall that well-worn and oft-repeated mantra: 'valuation is an art and not a science'. This particular adage was then, and definitely is now, an excuse for occasional intellectual laziness and an attempt to endow that particular skill with a mystique which it does not deserve in the light of the current requirements for comparables, devaluation and justification of valuations that are, quite rightly, nowadays needed to provide some sort of audit trail.

It is suggested that for too long a similar regime has existed for too many surveyors carrying out surveys, ie reports on condition. Some surveyors (the writer sometimes included) have relied on an 'artistic' diagnosis of, and explanation for, defects in the mistaken belief that it was too difficult to do the maths: 'leave it to the structural engineers, they're the brainy ones'.

This paper does not pretend to be, nor can it be, a definitive guide to this particular subject. It is more a signpost to some of the published information and documentation which has been available for years. It is suggested that it is time, with the advent of surveys for the vast majority of residential sales, for surveyors to start applying some or more 'science', based on those items of information which can be used as benchmarks.

With a general requirement from 2007 to consider dwellings much more from a standpoint of 'condition' (ie based on a survey) rather than with a view to 'value', for many surveyors there is likely to be a need to embrace, or re-embrace, the concept of 'life-long learning' in preparation for the change of emphasis. In (some of) the words of a politician now gone to a higher place 'go back to your textbooks and prepare for Home Inspections'.

(C) Larry Russen 2005

\section{References}

Burkinshaw, R. and Parrett, M. (2003) Diagnosing Damp, RICS Business Services Ltd, London, UK. Dickinson, P.R. and Thornton, N. (2004) Cracking and Building Movement, RICS Business Services Ltd, London, UK.

RICS Guidance Note for Building Surveys, 2nd Edition (2004) London, UK. 